\title{
Hydrocephalus: Electrocardiographic Localization of the Catheter in Ventriculo-atrial Shunts
}

\author{
G. BROCKLEHURST, J. R. W. GLEAVE, R. A. MILLAR, and AILEEN K. ADAMS \\ From the Department of Neurological Surgery and Neurology, and the Department of Anaesthetics, \\ Addenbrooke's Hospital, Cambridge
}

Among the surgical methods used in the treatment of hydrocephalus, procedures in which the cerebrospinal fluid from the ventricular system is drained through a valve directly into the venous side of the systemic circulation are now well established. However, the advantages of a low operative mortality and a high initial rate of success in the control of the hydrocephalus must be weighed against the fact that revision of these shunts is frequently necessary (Scarff, 1963). A common cause of this is the blockage of the lower end of the shunt, which occurs when the catheter is situated in vessels of relatively small lumen such as the innominate or internal jugular vein, whereas catheters situated well within the right atrium and surrounded by a relatively large volume of turbulent blood continue to drain freely. The initial siting of the cardiac catheter well within the right atrium is clearly important, and particularly so in infants and children in whom the catheter is drawn out of the atrium into the smaller veins by natural body growth. Methods involving the direct measurement of the length of catheter from the site of insertion, or the localization of the opacified catheter tip by radiographs taken during operation, are dependent upon the assumption of a fixed relation between the atrium and anatomical or radiological landmarks-an assumption that many radiologists consider to be unjustified, certainly in the infant. Furthermore, the relationship of the catheter tip to the vertebral bodies alters considerably with different $x$-ray projections. The relationship of the catheter tip to the cardiac outline can sometimes be determined on good radiographs, when the catheter tip is well opacified. Localization by this method requires a high standard of operative radiography with rapid repetition of films, dye injection into the catheter, and some inaccurate assumptions regarding the position of the atrium in

Received July 26, 1966. the cardiac shadow of the infant. This paper describes the use and reliability of an electrocardiographic method for localization of the tip of the catheter.

Electrocardiographic recordings using an intracardiac catheter as a recording electrode (known variously as intracardiac electrography, or intracavity electrocardiography) have been extensively investigated since 1945, mostly in the course of studies upon infants with congenital heart lesions. The findings were fully reported by Watson (Watson, 1962, 1964a, b) who measured the pressure and electric changes simultaneously, and showed that in a catheter drawn through the right atrium into the inferior vena cava, there was a gradual change in the polarity of the $P$ wave. This was negative high in the atrium, biphasic in the midcavity, and positive low in the chamber. These changes were constant and a reflection of the position of the recording electrode relative to the wave of atrial excitation, which is moving away from the tip of the catheter in the upper part of the atrium and travelling towards it in the lower part (Watson, 1964a).

Mark and Sweet (1960) first reported the application of this type of electrocardiography to localization of the cardiac catheter in ventriculo-atrial shunts. They used the electrocardiograph to indicate the passage of the catheter tip into the right ventricle by the observation of the extrasystoles. Robertson, Schick, Morgan, and Matson (1961) published an account of the technique used in 38 patients; the standard lead I components were taken and the left arm electrode was attached to the cardiac catheter. This arrangement produced an ECG with a downward deflection of the $P$ wave in the great veins of the neck, a notched $P$ wave in the superior vena cava and upper atrium, a biphasic pattern in the mid-atrium, and reversal of the $P$ wave in the lower part of the atrium. McClaurin, 
Glass, and Kaplan (1963) gave an account of a method using the chest lead attached to the cardiac catheter, and reported their results in 52 patients. The alterations in the $P$ wave were the same as those recorded by Robertson et al. (1961). Post-operative radiographs showed positions in relation to the vertebral column, which ranged from $\mathrm{T} 5$ to $\mathrm{T} 8$. Richards and Freeman (1964) used a simpler method of recording in over 350 cases: the lead II components were employed, the right arm lead being attached to the cardiac catheter and the left leg lead remaining on the limb. They found that a normal lead II ECG pattern was obtained when the catheter was in the superior vena cava (i.e. an upright $P$ wave) and that at the junction of the superior vena cava with atrium the $P$ wave became tall and notched. The notched $P$ wave became highest in the middle of the atrium and in the lower atrium the $\mathbf{P}$ wave became biphasic. They stated that the $P$ wave became inverted in the inferior vena cava, but no evidence is adduced in their paper to confirm their suppositions as to the actual sites of these $P$ wave changes.

In our series of 70 cases of ventriculo-atrial shunting operations, using the Pudenz Heyer Valve and ECG control, we have based our assumptions regarding the site of the $\mathbf{P}$ changes on the evidence produced by Watson (1964b). Our technique of recording, however, produces a complex similar to that of a lead II ECG when the catheter is in the great veins of the neck, i.e. an upright $P$ wave. This then undergoes the changes described by Watson but with a reverse polarity. Tall and spiked, biphasic, and inverted correspond, respectively, to upper atrium, middle atrium, and low atrium or inferior vena cava.

\section{Method}

The Pudenz Heyer Shunt is made of silicone rubber. There is a cardiac catheter containing a non-return valve in the lower end: to this is attached a catheter which drains CSF from the lateral ventricle of the brain, and the two are joined via a small spherical reservoir which fits into a burr hole in the skull; this reservoir can be used as a device for flushing the shunt and also indicates the site of any blockage by its behaviour on compression. At the start of each operative procedure the opening pressure of the cardiac catheter is assessed. Then a blunt-ended metal needle is firmly inserted into the upper end of the cardiac catheter, which is flushed with normal saline to ensure freedom from all air bubbles, and left immersed with its attached syringe in a bath of normal saline until required. Attention to these details and the use of dry towels under the exposed cardiac catheter and recording lead have enabled us to obtain good conductivity and satisfactory recordings without the use of a metal stylet, as in the method described by Richards and Freeman (1964), or of twice normal saline as described by other authors. When the vein selected for the insertion of the cardiac catheter has been exposed in the upper neck, the catheter and attached syringe are placed on the dry gauze squares on the small Mayo table above the patient. One end of a pre-sterilized wire lead is connected by an alligator clip to the metal needle inserted in the catheter and the other end of the lead is passed outside the sterile field to the anaesthetist. For the recording in the majority of cases the 'reverse' lead I components have been used. In this arrangement the right arm lead is attached to the cardiac catheter, and the left arm lead to the right arm. Stainless steel needles inserted subcutaneously are more convenient electrodes than the standard metal plates requiring electrode jelly. In other cases we have used the lead II components as outlined above. The syringe attached to the cardiac catheter is used to inject fresh saline if it is required to improve electrical conductivity. The ECG is displayed on an oscilloscope and recorded on a direct writer. The cardiac catheter is then passed downwards from the neck pausing frequently to watch the changing ECG pattern. Using the lead I reversed or lead II method, the upright $P$ wave becomes initially peaked, then tall and notched, then biphasic, and finally inverted. In the majority of cases we have left the cardiac catheter where the $P$ wave is displayed as tallest and notched, but more recently we have been leaving it where the $\mathbf{P}$ wave is biphasic. In accordance with the experimental evidence quoted above we believe that these points represent upper and middle atrium, respectively.

\section{TABLE I}

Ventriculo-atrial Shunt: Localization of Atrial Catheter Using Electrocardiographic Control. Cases of Hydrocephalus Operated Upon, Grouped According to Cause

\begin{tabular}{|c|c|c|c|c|c|}
\hline & & & $\begin{array}{c}\text { Primary } \\
\text { Operation }\end{array}$ & \multicolumn{2}{|c|}{ Revisions } \\
\hline $\begin{array}{l}\text { Meningomyel } \\
\text { Hydrocephalu } \\
\text { Congenital hy } \\
\text { Post-meningit } \\
\text { Benign aqued } \\
\text { Tumours .. } \\
\text { Head injuries }\end{array}$ & $\begin{array}{l}\text { les } \\
\text { ith } \\
\text { cep } \\
\text { yddr } \\
\text { ster } \\
\text {. } \\
\text {. }\end{array}$ & $\begin{array}{l}\text { types) } \\
\text { th trauma } \\
\text { us } \\
\text { phalus : } \\
\text { s } \\
\text {.. } \\
\text {.. }\end{array}$ & $\begin{array}{r}33 \\
10 \\
7 \\
3 \\
2 \\
5 \\
3\end{array}$ & $\left.\begin{array}{l}6 \\
1 \\
0 \\
0 \\
0 \\
0 \\
0\end{array}\right\}$ & $\begin{array}{l}\text { children } \\
\text { adults }\end{array}$ \\
\hline Total & $\ldots$ & .. & 63 & 7 & \\
\hline
\end{tabular}

\section{Results}

In Table I the cases of hydrocephalus treated have been grouped according to their cause, and it will be noted that among 70 cases there are 10 adults. Fig. 1 shows the pattern of changing $P$ wave as the catheter tip is advanced downwards, and position 4 is slightly in advance of that in position 3 and shows the $P$ wave biphasic. Position 5 in Fig. 1 shows an inverted $P$ wave correlated with the measured length of the catheter $15 \mathrm{~cm}$. from the neck incision, and a 


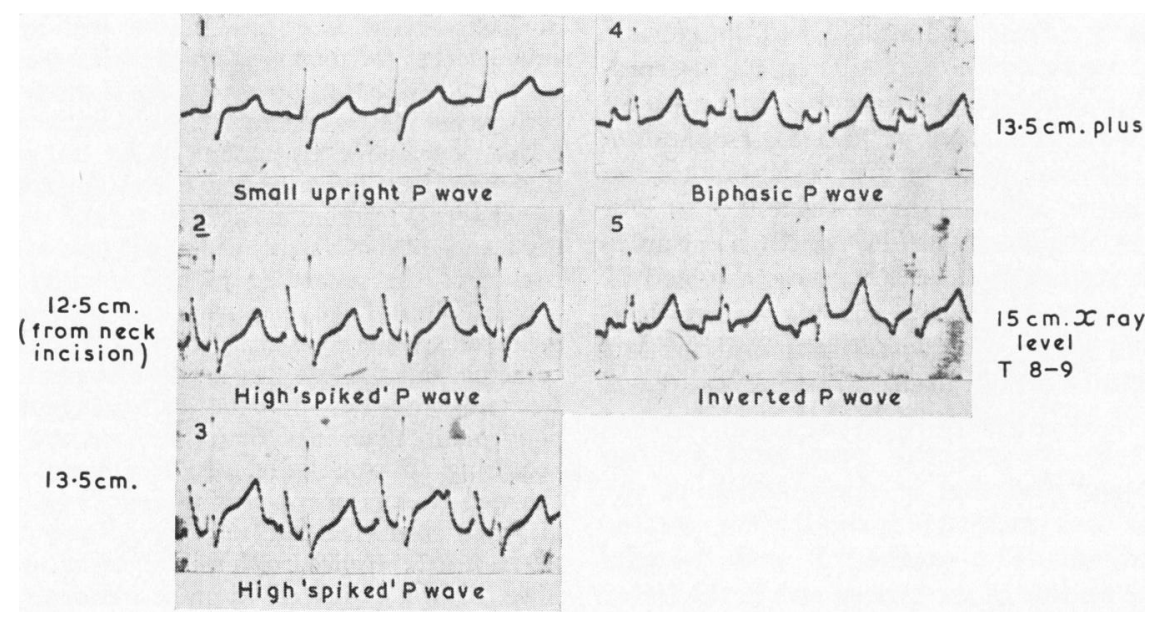

FIG. 1.-P wave changes with increasing length of catheter from neck incision in infant.

radiographic check showing the tip between the eighth and ninth thoracic vertebrae. Fig. 2 shows the correlation of some of the $\mathbf{P}$ wave changes with the position of the lower end of the cardiac catheter demonstrated radiographically, using Hypaque injection on the operative table. Table II shows the correlation of $\mathbf{P}$ wave changes with the vertebral levels assessed on operative and post-operative $x$-ray films in 39 cases. It will be seen that though the tall notched $P$ wave corresponds most frequently with $\mathrm{T} 7$, the biphasic $P$ wave with $T 8$, and the inverted $\mathbf{P}$ with a level below this, there is a considerable range of vertebral levels for any one particular end-point. The implication is that in any one particular case the acceptance of certain vertebral levels as representing the anatomical position of the

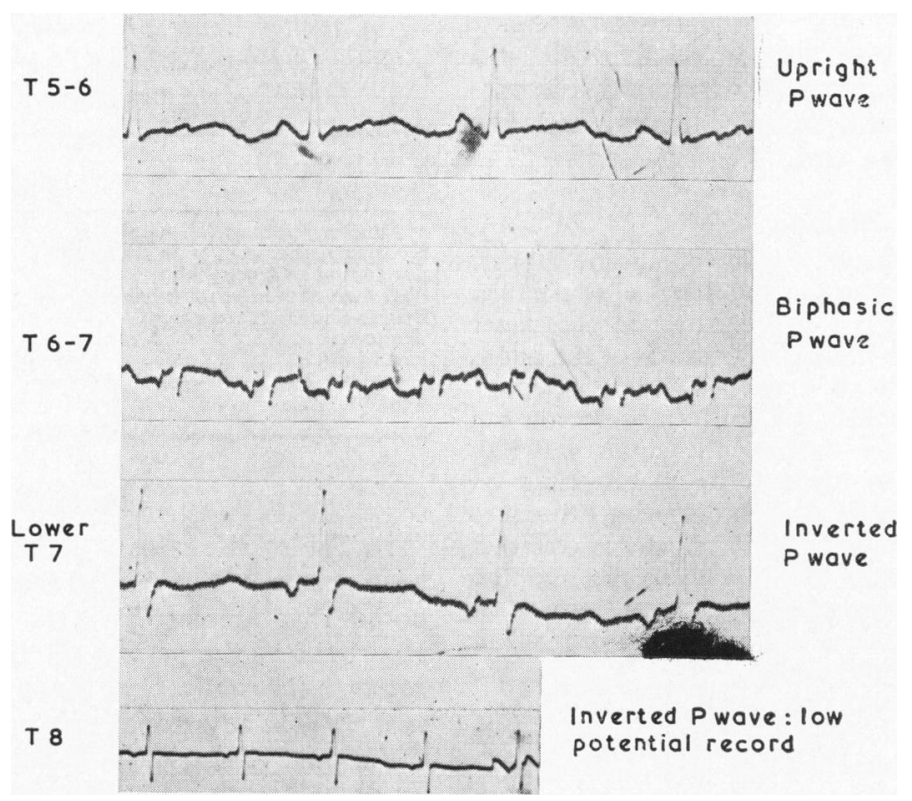

Fig. 2. $-P$ wave changes correlated with vertebral levels by $\mathrm{x}$-ray control (infant) during operation. 


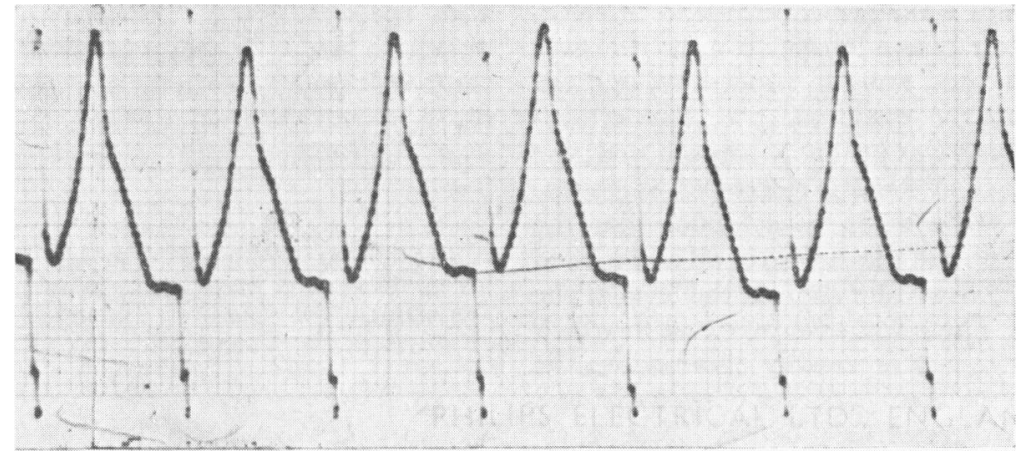

FIG. 3.-Catheter in ventricle. (No $P$ wave, large $Q R S$, gross abnormal $T$ wave.)

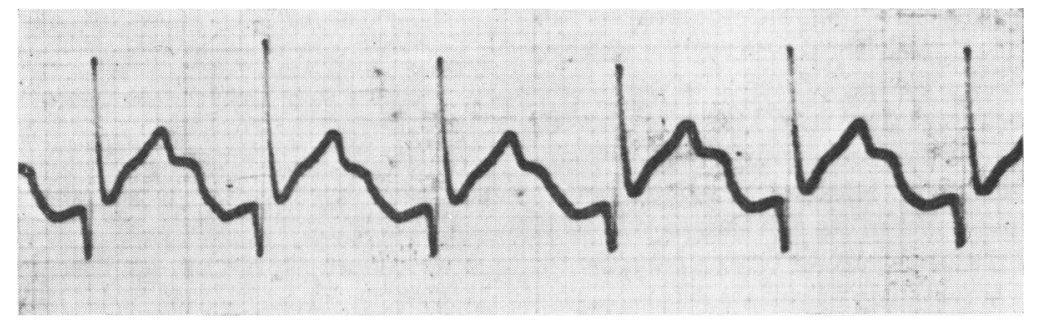

FIG. 4.-Catheter in coronary sinus. (Abnormal T P wave complex.)

atrium and thereby determining the radiographic siting of the lower end of the shunt may result in considerable inaccuracy.

A characteristic record is also seen when the catheter passes into the right cardiac ventricle rather than into the inferior vena cava, and this is illustrated in Fig. 3. (See Watson, 1962, where the same phenomenon is shown with the polarity reversed.) Fig. 4 shows the pattern associated with the catheter passing into the coronary sinus (Watson, 1964a; Richards and Freeman, 1964).

The method has proved technically satisfactory in 65 of the 70 cases, and has been performed with increasing ease and speed. In 60 of these the

\section{TABLE II}

Correlation of $P$ Wave End-point with Vertebral Levels in 39 Cases

\begin{tabular}{c|c|c|c}
\hline $\begin{array}{c}\text { Vertebral } \\
\text { Levels }\end{array}$ & $\begin{array}{c}\text { High Upright } \\
\text { Notched P }\end{array}$ & $\begin{array}{c}\text { Biphasic } \\
\mathbf{P}\end{array}$ & $\begin{array}{c}\text { Inverted } \\
\mathbf{P}\end{array}$ \\
\hline T6 & 4 & 2 (2 adults $)$ & 0 \\
T7 & 9 & 4 (1 adult $)$ & 0 \\
T8 & 5 (1 adult) & 9 (2 adults $)$ & 2 \\
T9 & 0 & 1 & 3 \\
\hline & 18 & 16 & 5 \\
\hline
\end{tabular}

catheter tip has been adequately seen on radiographs taken either at operation or in the post-operative period in order to check the electrocardiographic results (Fig. 5).

In 5 of the 70 cases there was technical failure. In 3 an adequate intracavity ECG could not be

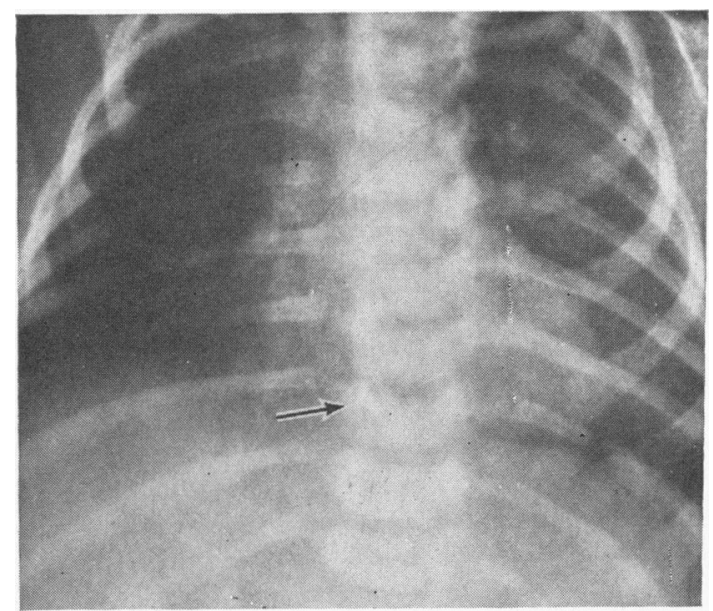

Fig. 5.-Post-operative chest $\mathrm{x}$-ray film showing catheter tip (arm) opposite 9th thoracic vertebra. 
obtained because of unidentified electrical interference. In a further case a left-sided neck vein was used for a complicated revision procedure, and the catheter could not be made to enter the left innominate vein which was probably thrombosed; the failure to obtain a characteristic electrocardiographic change could now be taken as evidence that the catheter had not entered the atrium at all and indeed the post-operative $x$-ray film showed the level of the shunt to be T4. There was one early case in which an inverted $P$ wave was repeatedly obtained on the oscillograph, but the trace was of low potential and there was no written ECG check. The postoperative $x$-ray film showed the catheter to be at C7, and in retrospect it was obvious that a unipolar ECG from the arm electrode was displayed rather than a record from the catheter. Such a unipolar lead can always be recognized, first by the very low voltage tracing, and secondly by the presence of 50 cycles interference superimposed on it. This case was an adult with hydrocephalus following a head injury, and we now realize that in adults the catheter has to be advanced to just short of its full length before it reaches the atrium and the ECG changes occur.

\section{Summary}

An electrocardiographic technique for the localization of the atrial catheter of the Pudenz Heyer apparatus is described. Experience in 70 operations shows that the technique can be performed reliably, with speed and with minimal disturbance of the operative field. It seems likely that the position of the tip of the catheter in the atrium is more accurately given by the changes in electrical potential than by $x$-ray correlation with a predetermined vertebral level.

The authors are grateful to $\mathrm{Mr}$. Walpole Lewin for his advice in the preparation of this paper, and to the Department of Medical Illustration, Addenbrooke's Hospital for the Tables and $x$-ray picture.

\section{REFERENCES}

McClaurin, R. L., Glass, I. H., and Kaplan, S. (1963). Ventriculoatrial shunt for hydrocephalus: electrocardiographic control for accurate placement. Amer. F. Dis. Child., 105, 216.

Mark, V. H., and Sweet, W. H. (1960). Ventriculo-atriostomy; a technical note: the accurate placement of the distal end of the shunt into the right atrium without $x$-ray control. Neurochirurgia (Stuttg.), 3, 115.

Richards, C. C., and Freeman, A. (1964). Intra-atrial catheter placement under electrocardiographic guidance. Anesthesiology, $25,388$.

Robertson, J. T., Schick, R. W., Morgan, F., and Matson, D. D. (1961). Accurate placement of ventriculo-atrial shunt for hydrocephalus under electrocardiographic control. f. Neurosurg., 18, 255.

Scarff, J. E. (1963). Treatment of hydrocephalus: an historical and critical review of methods and results. $f$. Neurol. Neurosurg. Psychiat., 26, 1.

Watson, H. (1962). Intracardiac electrography in the investigation of congenital heart disease in infancy and the neonatal period. Brit. Heart F., 24, 144.

- (1964a). Electrode catheters and the diagnostic application of intracardiac electrography in small children. Circulation, 29, 284.

(1964b). Intrinsicoid atrial P-wave deflections in unipolar intracardiac electrograms. Amer. Heart $\mathcal{F}$., 68, 3. 